\title{
Sepsis diagnosis and treatment using nanomaterials
}

\author{
Jaesung Lim $^{1,2} \cdot$ Yun Young Lee ${ }^{3} \cdot$ Young Bin Choy ${ }^{3} \cdot$ Wooram Park ${ }^{4}$ Chun Gwon Park ${ }^{1,2,5,6}$ C
}

Received: 31 March 2021 / Revised: 10 June 2021 / Accepted: 4 July 2021 / Published online: 12 July 2021

(c) Korean Society of Medical and Biological Engineering 2021

\begin{abstract}
Sepsis is a life-threatening reaction that occurs when the body's severe response to an infection damages the host's own tissues. Sepsis has been globally recognized as a fatal disease. Rapid treatment of sepsis requires prompt identification, administering antibiotics, careful hemodynamic support, and treating the cause of the infection. Clinical outcomes of sepsis depend on early diagnosis and appropriate treatment. Unfortunately, current sepsis diagnosis and treatment, such as polymerase chain reaction-based assay, blood culture assay, and antibiotic therapy, are ineffective; consequently, sepsis-related mortality remains high and increases antimicrobial resistance. To overcome this challenge, nanotechnology, which involves engineering at a nanoscale, is used for diagnosing and treating sepsis. Preclinical models have shown protective effects and potential utility in managing septic shock. Furthermore, nanotechnology treatments based on diverse materials result in the effective treatment of sepsis, improving the survival rate. In this review, we present an overview of the recent research advancements in nanotechnology to diagnose and treat sepsis with a brief introduction to sepsis.
\end{abstract}

Keywords Sepsis $\cdot$ Infection $\cdot$ Nanotechnology $\cdot$ Diagnosis $\cdot$ Treatment

Jaesung Lim and Yun Young Lee have contributed equally to this work.

Chun Gwon Park

chunpark@skku.edu

1 Department of Biomedical Engineering, SKKU Institute for Convergence, Sungkyunkwan University (SKKU), Suwon, Gyeonggi 16419, Republic of Korea

2 Department of Intelligent Precision Healthcare Convergence, SKKU Institute for Convergence, Sungkyunkwan University (SKKU), Suwon, Gyeonggi 16419, Republic of Korea

3 Department of Biomedical Engineering, Seoul National University College of Medicine, Seoul 03080, Republic of Korea

4 Department of Biomedical-Chemical Engineering, The Catholic University of Korea, Bucheon, Gyeonggi 14662, Republic of Korea

5 Biomedical Institute for Convergence at SKKU (BICS), Sungkyunkwan University, Suwon, Gyeonggi 16419, Republic of Korea

6 Center for Neuroscience Imaging Research, Institute for Basic Science (IBS), Suwon, Gyeonggi 16419, Republic of Korea

\section{Introduction}

Sepsis is defined as a condition in which the body's dramatic response to an infection from bacteria, viruses, parasites, or fungi results in damage to healthy tissues. Sepsis is a clinical syndrome leading to organ dysfunction caused by a dysregulated host immune response to infection (2016) [1]. If left unchecked, it can progress to septic shock, a severe condition that occurs when blood pressure drops and organs shut down [2]. Sepsis is a major global health priority contributing to high mortality. It often triggers various symptoms, including high fever, elevated heart rate, and fast breathing, leading to severe organ problems and even death [3]. Every year, approximately 31.5 million sepsis cases are reported worldwide, of which about 5.3 million die annually due to a mortality rate as high as $30 \%$ [4]. Consequently, sepsis remains a considerably severe problem. Recently, coronavirus SARS-CoV-2, the cause of COVID-19, has been closely related to sepsis. Most SARS-CoV-2-infected patients show immune dysregulation, hyperinflammatory response, and alterations in coagulation that further contribute to sepsis [5]. SARS-CoV-2 related sepsis has potential crosstalk with neutrophil extracellular traps (NETs), which comprise extracellular DNA decorated with histones and antimicrobial proteins. NETs are released due to inflammation. The process 
of NET formation by a neutrophil is called NETosis. The process plays a role in controlling pathogens but has a detrimental effect on cardiovascular and pulmonary health [6]. Intravascular NETosis in COVID-19 infection could play a role in vasculature complications, where thrombotic disease can drive organ damage. This phenomenon is known to cause complications leading to sepsis. Severe sepsis patients are associated with devastating complications to acute respiratory distress syndrome (ARDS) with an increased risk of vascular hyperpermeability, pneumonia, sepsis, and ultimately death [7].

Sepsis occurs through various mechanisms. It is a clinical disease with biological, biochemical, and physiological abnormalities caused by an immune system dysfunction (Fig. 1). Sepsis is characterized by systemic inflammatory response syndrome (SIRS), microcirculatory derangements, and multiple organ dysfunction [8]. Infection is initiated by immune cells recognizing pathogen or damage-associated molecular patterns (PAMPs/DAMPs) $[9,10]$. When pathogens are invaded, the complement system, an innate immune system, is activated [11]. Neutrophils migrate to the infection site, and the endothelial cells present at the site of inflammation are expressed as adherent molecules on their surface. Other immature immune cells such as monocytes are differentiated into macrophages in situ, releasing pro-inflammatory cytokines [12]. These pro-inflammatory cytokines were strictly regulated, and homeostasis is restored after recovering tissue injuries [12-14]. Tissues far from the initial infection show symptoms of inflammation, including vasodilation, increased microvascular permeability, and leukocyte accumulation [15]. Although inflammation is an essential host response, the onset and progression centers of sepsis upon a "dysregulation" of the typical response, usually with an increase in both pro-inflammatory and antiinflammatory mediators called a cytokine storm, initiating a chain of events that leads to widespread tissue injury [8, 16]. According to a recent study, the body's response to the endotoxin is characterized by releasing cytokines and other inflammatory mediators, leading to a generalized inflammatory response. Mononuclear and endothelial cells activated by the endotoxin induce platelet-activating factors, and coagulation proteases induce additional pro-inflammatory stimuli [17]. The mutual reinforcement of inflammatory and coagulation cascades leads to tissue damage and eventual septic shock [18]. Another study described that the SIRS is characterized by excessive production of pro-inflammatory mediators [19]. The compensatory anti-inflammatory response (hyperinflammatory status) syndrome (CARS) progressively suppresses this early response [20].

Conventional diagnosis of sepsis requires microbiological cultures from blood or urine for the detection of sepsis markers. Microbiological cultures offer helpful information; however, there is a limit for long incubation times, making them unsuitable for rapid diagnostics.

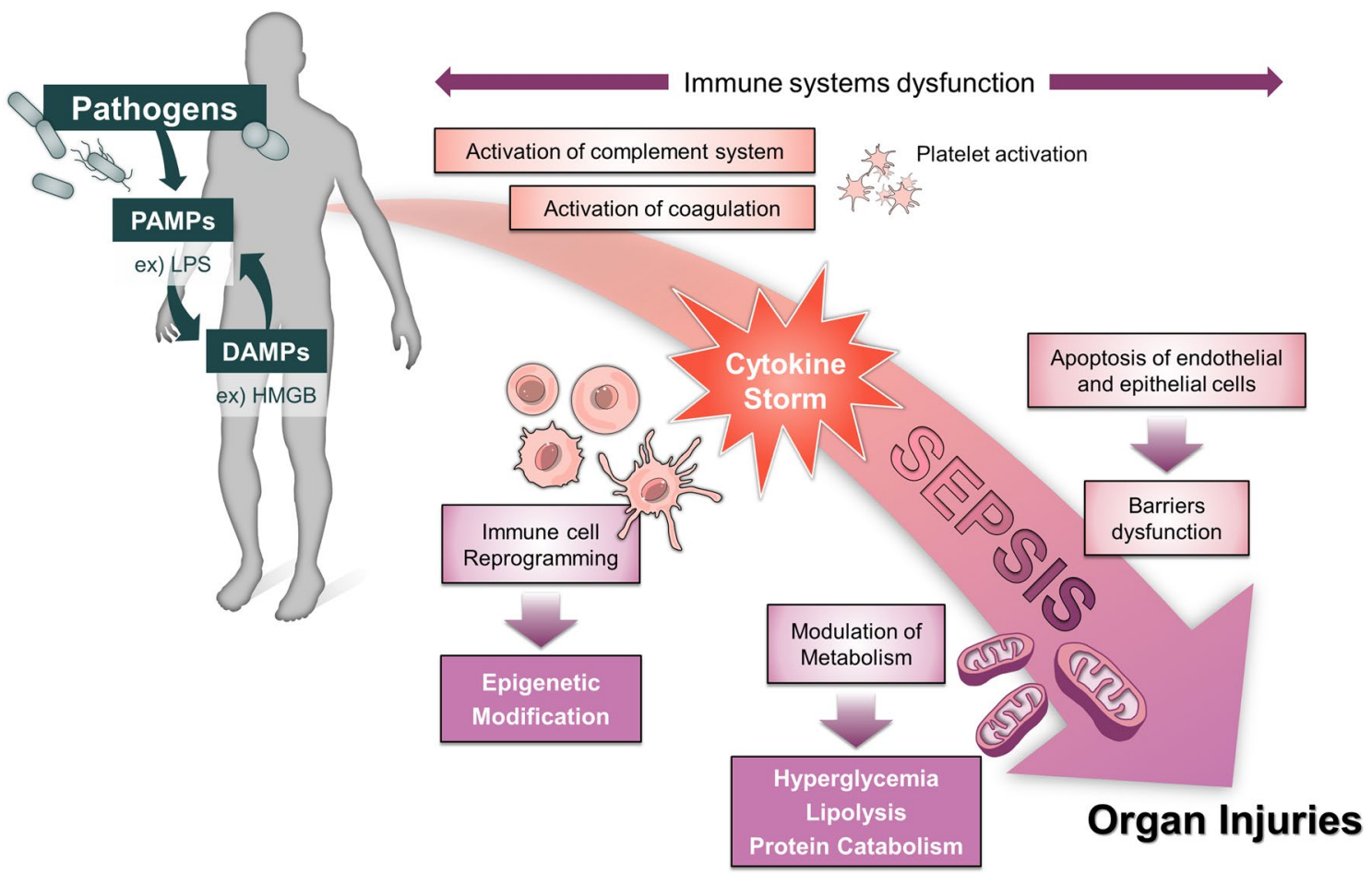

Fig. 1 Schematic illustration of the sepsis players and pathophysiological events occurring in sepsis. Copyright 2020 EMBO Molecular Medicine. Reproduced with permission ref. 10 
The polymerase chain reaction (PCR) system is an established technique that offers high sensitivity, reproducibility and multiplies DNA sequences found within biofluids by several orders of magnitude to allow detection of target pathogen DNA sequences. However, there are technical limitations to using PCR. The potential for high laboratory analytical sensitivity and high risk of sample contamination could produce false-positive results due to amplifying contaminant DNA. Commonly available contrast agents and biomarkers such as $\mathrm{C}$-reactive protein (CRP) and procalcitonin (PCT) may be used to facilitate the detection of proteins and nucleic acids. However, CRP and PCT have low specificity for diagnosing sepsis in patients with co-developing sepsis episodes and are not a reliable indicator of prognosis and systemic inflammation [21, 22].

Sepsis therapies focus on early recognition, treatment of infection, fluid and metabolic resuscitation, and endorgan support, including mechanical ventilation and stabilization of hemodynamics [23, 24]. Sepsis is a condition caused by bacterial infections. Therefore, it is treated with antibiotics [25]. Information about the type of bacteria that caused sepsis and the progression of the condition can significantly affect the patient's survival. Various treatments such as infection control, immune modulation, and metabolic support are performed [26, 27]. However, due to the complicated sepsis pathology, the successful delivery of antibiotics to the target site is generally not achieved; consequently, the drug's pharmacokinetics change to an extent lower than that before sepsis [28]. In addition, because of the toxicity of the antibiotic, the blood vessels are damaged, and intestinal microorganisms are destroyed [29, 30]. Although the prognosis of sepsis treatment is achieved through antibiotic treatment, antibiotic-resistant sepsis might occur due to other types of bacteria or specific groups of microorganisms [31]. Hence, advanced sepsis diagnostic platforms and therapeutic strategies are urgently required for improving clinical outcomes and reducing mortality. Nanotechnology has been widely used in the biomedical field, especially as a means of diagnosis and treatment of various diseases such as sepsis [22]. Nanotechnology has been also widely used and developed as a drug delivery technology that increases the treatment efficiency of various diseases in the body because it can be injected via a intravenous injection [28]. These applications may suggest promising solutions for more accurate diagnosis and treatment tools for sepsis. Significant studies in the last three years have raised the potential of powerful nanotechnology for the efficient diagnosis and treatment of sepsis (Fig. 2). In this review, we summarized the cases of applying nanotechnology to the diagnosis and treatment of sepsis.

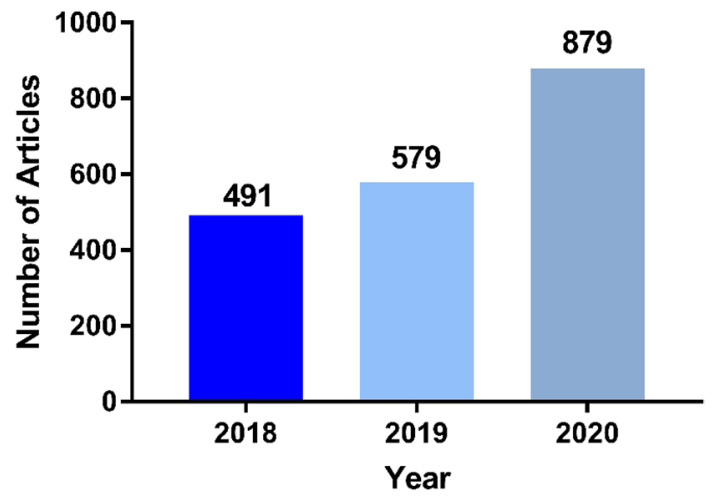

Fig. 2 Distribution of published articles for sepsis-related nanotechnology (2018-2020)

\section{Nanotechnology for sepsis diagnosis}

Diagnosing sepsis in early-stage patients is challenging because the onset of clinical signs and symptoms is not specific. In addition, proteins for diagnosis have low concentrations in body fluids and have long incubation periods, making it difficult to detect blood probes. Thus, diagnosis depends on clinical manifestations and blood tests for detecting inflammation response-related blood biomarkers such as CRP and PCT. A progressive decline in CRP or PCT concentrations can be used to inform decisions on the early discontinuation of antibiotic therapy without significant risks. However, increasing CRP concentration in the first two days of therapy suggests that antibiotic therapy may be ineffective and needs reevaluation. Using PCT concentration in an antibiotic escalation strategy is not sufficient because it results in worse outcomes. Thus, clinical decisions should not be based on the concentration of a single biomarker [22]

Conventional methods require medically trained personnel and a multi-step analysis, making them time-consuming and costly. Instrumentation of such methods is not compliant with minimization, and such methods are laboratory-based. Several nanoscale platforms have been proposed as a potential carrier to improve sepsis recognition (Fig. 3).

The employment of nanoparticles (NPs) for diagnostic and therapeutic purposes offers excellent potential due to their regulatory properties (e.g., size, shape, surface chemistry, charge, and composition) and their capacity for surface functionalization (with ligands, antibodies, and targeting molecules), allowing targeted and selective binding [32]. To improve the biodistribution of existing therapeutics, nanotechnology drug delivery systems can be engineered by improving the drug's bioavailability, efficacy, and stability at the target site [33]. Research on nanoscale strategies for addressing the prominent disruption associated with sepsis has been conducted according to these possibilities. Several NPs have been investigated to allow the diagnosis 


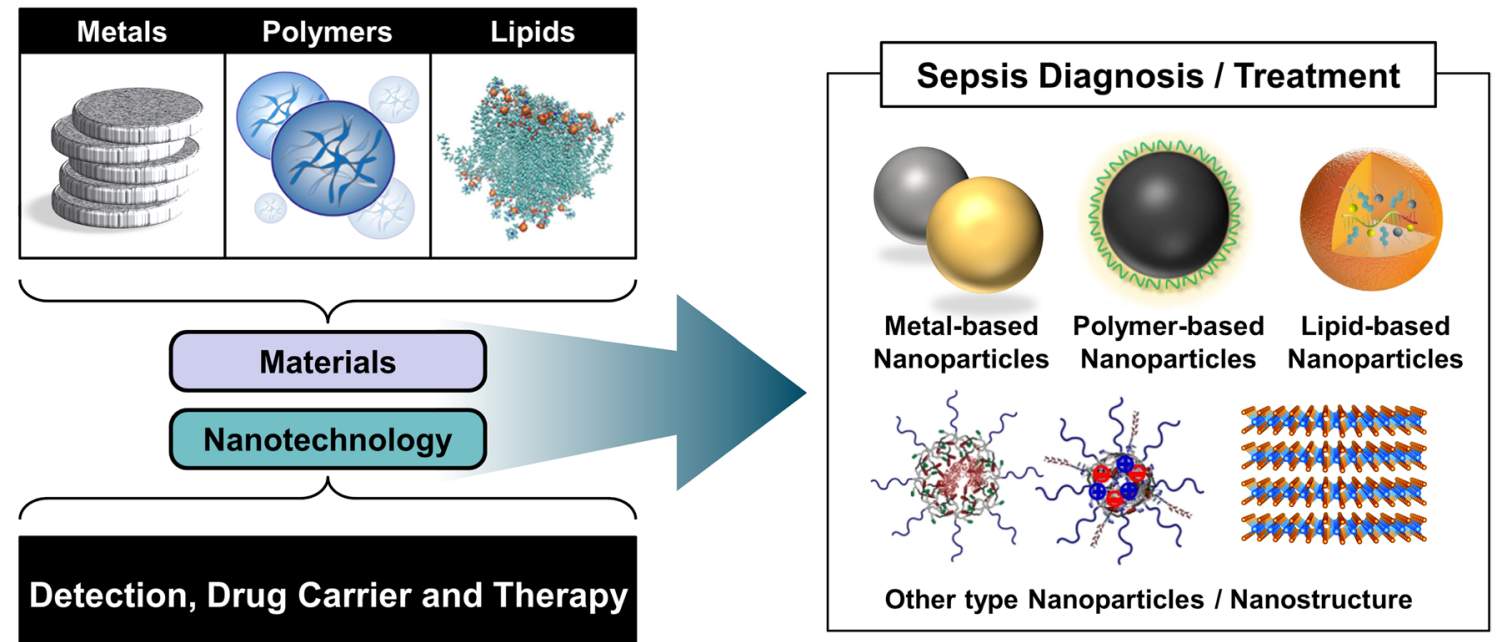

Fig. 3 Several biomaterial-based nanotechnologies for sepsis diagnosis and treatment. Reproduced with permission ref. 56. Copyright 2020 Advanced Science. Reproduced with permission ref. 59. Copy-

of sepsis-related microbial infections such as magnetic NPs (MNPs), gold NPs (AuNPs), fluorescent NPs (silica and quantum dots QDs), and lipid-based NPs in addition to technologies such as lab on a chip, point of care (POC), biosensor in the development of accurate, fast and sensitive methods for sepsis detection [34]. Portable biosensors comprise an electrical detection system, and a disposable kit for blood processing can take IL-3 on magnetic beads and label it for the electrochemical reaction [35]. Detectors have been developed to measure electrical currents for IL-3 quantification. Biosensors applying NPs or other beads for diagnosing sepsis have been widely published.

NPs, defined as a particle of having a size range from 1 and $100 \mathrm{~nm}$ in diameter, have been proposed as carriers of sepsis diagnostics and treatments. Small-molecule drugs possess undesirable side effects and undergo rapid renal clearance and reduce residence time due to the spread throughout the body. NPs adjusting size and surface characterization have a longer circulation half-life and differential biodistribution profile than their free drug [36]. Nanotechnology has shown that high sensitivity, specificity, and complex diagnosis can meet these demands. However, the unique characteristics of NPs vary depending on what material it is made of. Currently, metal-based NPs such as gold or magnetic NPs are widely used for diagnosing sepsis (Fig. 4-1). They show promising results by being grafted into biosensors and POC technology (Table 1). In particular, AuNPs and AgNPs have unique optical and biochemical characteristics depending on the size and concentration of the NPs.

The AuNPs have been widely used as nanotechnology for theranostic application because of their biochemical advantages that offer precise control over physicochemical and right 2020 Nature Communication. Reproduced with permission ref. 68. Copyright 2020 International Journal of Molecular Sciences

optical properties. It showed multifunctional characterization in imaging, surface modification, and therapeutics and is biocompatible. AuNPs can be combined with liposomes or polymeric NPs that deliver a drug or large construct for high and efficient delivery and enhanced targeting properties [37]. Because of the gold NPs' optical, physical, and chemical properties, selective and specific identification of DNA/RNA sequences related to pathogens are possible. One example is that the bio-barcode assay is developed to detect protein and nucleic acid targets more sensitively. Bio-barcode detection technology using AuNPs is fast and straightforward in detecting small molecules; it is also costeffective [38]. The surface of AuNPs and the convenience and synthesis of DNA/RNA molecules, proteins, and other biomolecules serve as an optimal tool for testing target molecules. A study showed that gold NPs can help detect sepsis diagnostic markers, owing to the NP's higher sensitivity and quicker detection time [39]. Imaging-based plasmonic biosensing technology, which uses AuNPs, can be enhanced using gold nanohole arrays (Au-NHAs), which leads to a high sensitivity for protein detection and enhancement in single analyte resolution. The proposed method was implemented using a sandwich immunoassay measurement to detect clinical biomarkers of acute inflammatory diseases. This biosensing NP approach enables detecting $10 \mathrm{pg} / \mathrm{mL}$ of biotinylated bovine serum albumin (bBSA) and $27 \mathrm{pg} / \mathrm{mL}$ CRP [40]. This result was at least four orders of magnitude lower than the clinically relevant concentrations, making it a critical and fast approach paired with the large-area plasmonic sensor chips [40].

Another study demonstrated sensitive and rapid detection of pathogenic bacteria with POC microbial sensing based 
on AuNPs modified with azide and alkyne functional molecules. Exogenous $\mathrm{Cu}^{2+}$ was first captured and reduced to $\mathrm{Cu}^{+}$by pathogenic bacteria from detected samples, where $\mathrm{Cu}^{+}$subsequently acts as a catalyst to trigger the click reaction between the azide- and alkyne-AuNPs. These results in the NPs were aggregating, causing the solution to change color from red to blue. Based on this color change of the AuNP solution, POC detection of pathogenic bacteria can be obtained easily and quickly by simple observation, i.e., the color changing of the AuNPs solution [41]. This result showed outstanding potential for the early diagnosis of bacterial infections.

MNPs are also common in diagnostic medicine because they can be used in various ways through surface modification and separation by magnets. They suggested a nanosystem based on iron oxide MNPs functionalized with chlorin e6 molecules and bacterial species-identifiable aptamers $\left(\mathrm{Fe}_{3} \mathrm{O}_{4}\right.$-Ce6-Apt), reported for early diagnosis of sepsis. It has a comparable detection sensitivity; however, it significantly reduces the time required for diagnosis, revealing a significant potential for early sepsis diagnosis in clinical settings. In sepsis diagnosis, species identification and bacterial enrichment are two critical works because of the co-existence of giant blood cells and proteins in the early stages of sepsis and the low concentration of bacteria (about 10-100 cells per $\mathrm{mL}$ ) bloodstream. $\mathrm{Fe}_{3} \mathrm{O}_{4}$-Ce6-Apt nanosystem, a novel strategy, can simultaneously achieve blood bacterial species identification and magnetic enrichment in a single step. Furthermore, $\mathrm{Fe}_{3} \mathrm{O}_{4}$-Ce6-Apt nanosystem could easily detect enriched bacteria with the assistance of fluorescence microscopic determination [42].

Diagnostic technology using nanobead demonstrates impressive results. Markers for diagnosing sepsis include CRP, PCT, and IL-6. A recent study generally demonstrated that the PCT levels in healthy human serum are shallow and undetectable via standard methods; however, serum PCT concentration increases rapidly $(>100 \mathrm{ng} / \mathrm{mL}$ ) in response to pro-inflammatory stimulation severe infections like sepsis. They proposed an efficient homogeneous immunoassay for precisely detecting PCT for the early diagnosis of sepsis based on luminescent oxygen channeling assay technology, called AlphaLISA technology. They demonstrated that the novel PCT detection technique had developed a high sensitivity and yielded accurate results within a short period. It will be helpful for the prognosis and early screening of diagnosis for sepsis patients [43].

\section{Nanotechnology for sepsis treatment}

Recently, several NP systems have demonstrated excellent treating effects against sepsis in preclinical models, suggesting their potential efficacy in managing sepsis and septic shock. As antibacterial agents, NP systems can provide platforms to immobilize endotoxin adsorbents, interact with inflammatory cells to restore homeostasis, and detect sepsis biomarkers promptly [45]. However, even simply administering the drug tends to distribute it throughout the body, causing undesirable systemic effects or reducing the drug's circulation time. In limited conditions, the kidneys or macrophages (renal clearance, phagocytosis) rapidly remove the drugs from the body [46]. Several NP platforms have been proposed as potential carriers of anti-sepsis therapies owing to the unique properties of NPs, such as their small size, surface functionalization, and pharmacokinetic/biodistribution profiles [47]. NP systems can be easily surface-modified and conjugate with various molecules to their surface. This increased the circulation time in the body by preventing it from being removed by other immune cells, enabling the release of the drug-loaded inside using substances to target specific cells, inflammatory sites, and proteins $[48,49]$.

The progress of novel therapy of sepsis critically depends on the understanding of sepsis-related physiological mechanisms. Sepsis pathology comprises highly complicated and integrated responses, including activation of multiple cell types, inflammatory agents, and hemostatic systems [14]. During sepsis, lipopolysaccharide (LPS) was engaged with endothelium's toll-like receptor 4 (TLR4) or several inflammatory mediators (IL-6, TNF- $\alpha$, IL-1, kinins, and C5a) interact with their receptors. Therefore, the endothelium was activated, and later the sepsis cascade may be conditioned by other surrounding factors (hypoxia, low blood flow, temperature change, homeostasis imbalance, and hyperglycemia). The interaction of extracellular mediators with their receptors leads to the activation of downstream signaling pathways like mitogen-activated protein kinase (MAPK) and protein kinase $\mathrm{C}(\mathrm{PKC})$, which can promote posttranscriptional changes in cell function or alter gene expression profiles through several transcription factors, including NF- $\mathrm{KB}$ [50].

The overexpression of cell adhesion molecules in endothelium surfaces, such as E-selectin, P-selectin, Intracellular adhesion molecule 1 (ICAM-1), and vascular cell adhesion molecule 1 (VCAM-1), can elevate the adhesion, rolling, and transmigration of circulating leukocytes. Leukocyte-endothelial interactions further modulate the phenotype of these cells. During the activation process, nicotinamide adenine dinucleotide phosphate oxidase (NADPH oxidase) may induce the formation of reactive oxygen species (ROS), releasing nitric oxide (NO), and increase the cell permeability. Based on this fact, it is possible to treat sepsis through various strategies such as targeting the inflammatory region using TNF- $\alpha$ and ICAM- 1 or controlling the body's ROS level with NP manufacturing technology [51]. The NPs that proved effective for sepsis treatment are sorted by their physicochemical properties and size (Table 2). 

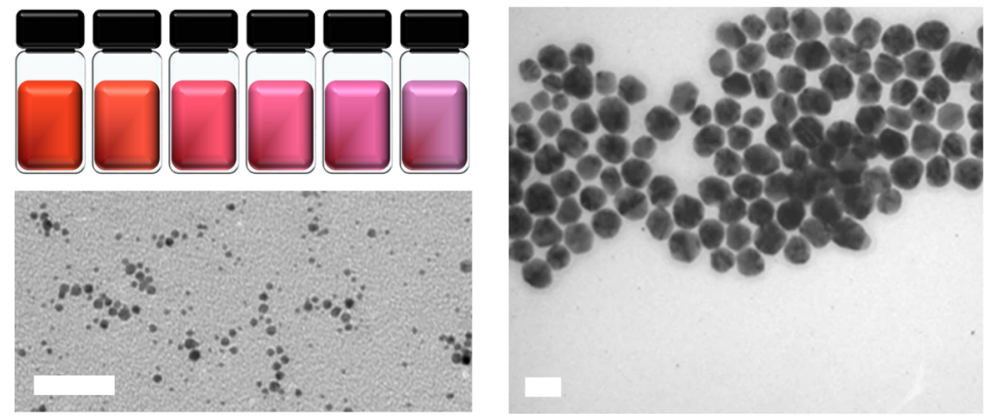

Gold NPs (AuNPs) Silver NPs (AgNPs)

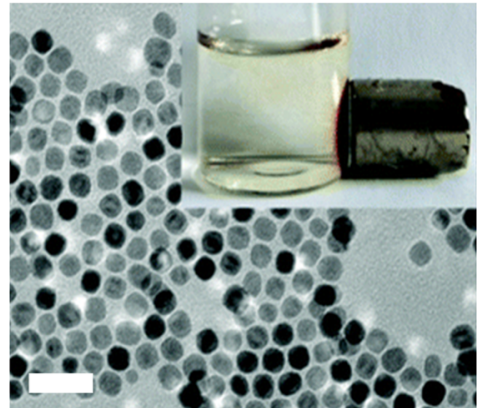

Iron oxide NPs

(A) Iron oxide NPs with extracorporeal photodynamic blood disinfection

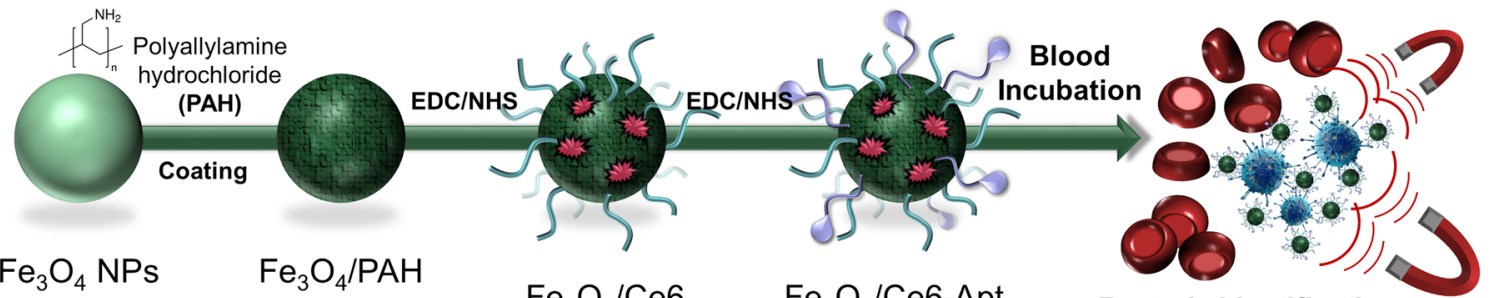

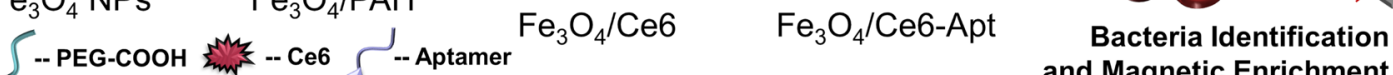
and Magnetic Enrichment

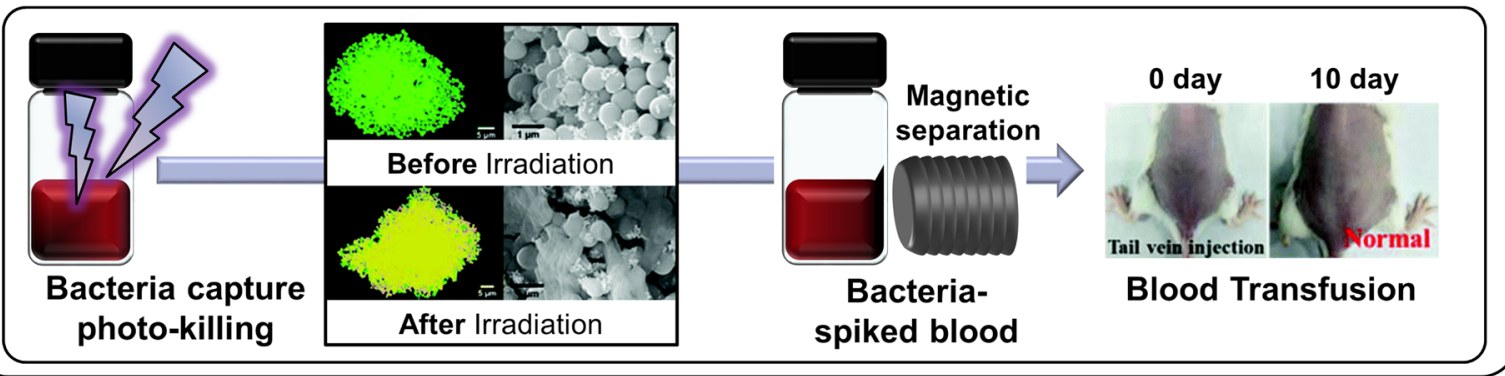

(B) mSPAM nanoassembly alleviation of LPS induced local and systemic inflammation

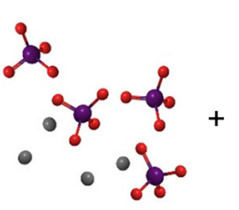

$\mathrm{KMnO}_{4}$

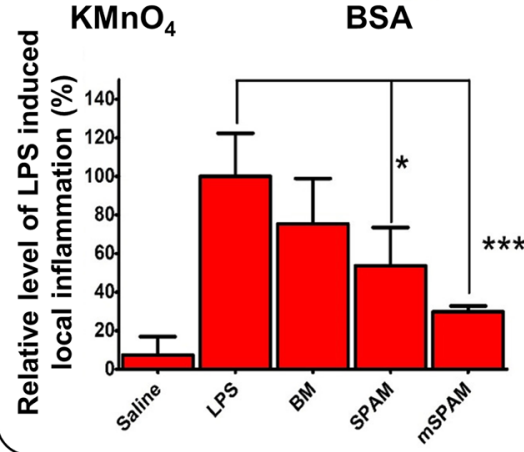

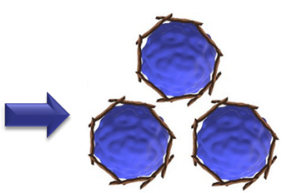

BSA-MnO2 (BM)
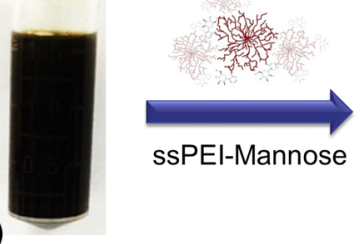

ssPEI-Mannose
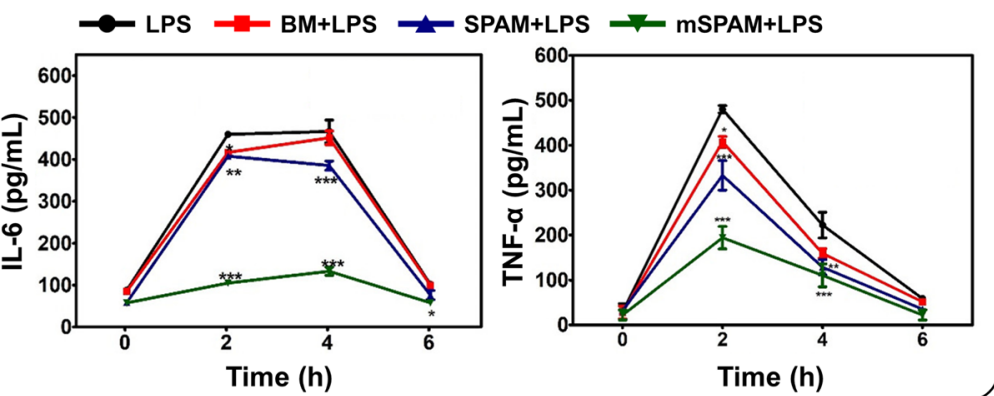
४Fig.4 1 Several types of metal-based NPs. Gold NPs (AuNPs), silver NPs (AgNPs), iron oxide NPs $\left(\mathrm{Fe}_{3} \mathrm{O}_{4}\right)$, and SPIONs. (scale bar: $50 \mathrm{~nm}$ ). 2 Metal-based NP with sepsis treatment. A $\mathrm{Fe}_{3} \mathrm{O}_{4} / \mathrm{Ce} 6-\mathrm{Apt}$ nanosystem identifies the sepsis-induced bacteria capable of early sepsis diagnosis. Bacteria-infected blood was treated with photoirradiation, and bacteria capturing NPs were separated by magnetic force. B mSPAM nanoassembly system synthesized by $\mathrm{BSA}-\mathrm{MnO}_{2}$ complex could reduce inflammation in the LPS-induced sepsis model. It was reproduced with permission from ref. 54. Copyright 2018 American Chemical Society

\subsection{Metal-based nanoparticle}

In recent years, metallic NPs in different medical applications, such as bioimaging, biosensors, target/sustained drug delivery, hyperthermia, and photoablation therapy, have received significant interest. Metal NPs are prepared from metal-based precursors; they can be synthesized by chemical, electrochemical, or photochemical methods. In chemical methods, the metal NPs are obtained by reducing the metal-ion precursors in the solution by chemical reducing agents [34]. These can adsorb small molecules and have high surface energy. In particular, AuNP/AgNPs were known to have antimicrobial effects. Several approaches incorporated these advantageous features of NP systems for preventing and treating sepsis [61].

AuNPs were demonstrated as an adjuvant therapeutic agent in one of the studies, with a proper antibiotic, attenuated cecal ligation, and puncture (CLP)-induced bacterial sepsis in mice [52]. AuNPs have a potential antibiotic effect and elicit the macrophage function toward the anti-inflammatory responses. In this study, the weak antibiotic effect of AuNP results of Escherichia coli (E. coli) colony reduction was demonstrated. In addition, AuNP increased M2 macrophages $\left(\mathrm{CD} 206^{+} \mathrm{F} 4 / 80^{+}\right.$cells) with IL-10 and decreased inflammatory cytokines (TNF- $\alpha$, IL-6, IL-1 $\beta$ ) in vivo sepsis model [52]. Another study employed 4,6-diamino2-pyrimidinethiol (DAPT) with AuNPs (D-Au NPs) to treat a bacterial infection induced by E. coli in gut. D-Au NPs recovered the gut intestinal microflora more effectively than levofloxacin without side effects from bacterial infections in mice models. D-Au NPs elevated the relative abundance of specific probiotics and protected the gut microbiome; thus, they were non-toxicity in the liver and kidney [62]. Furthermore, the AgNPs were utilized as antimicrobial materials to a gram-positive and negative bacterial infected model. It explained the clinical effect of combining with ultrasound that does not elicit systemic toxic effect [63].

MNPs, along with AuNPs and AgNPs were applied to a sepsis treatment model through various surface functionalization to evaluate their efficacy. As shown in Fig. 4-2A, surface-modified iron-oxide NPs, which are suggested as a nanosystem for early sepsis diagnosis and complete extracorporeal blood disinfection, conjugate with chlorin e6 molecules and bacterial species-identifiable aptamers $\left(\mathrm{Fe}_{3} \mathrm{O}_{4}\right.$-Ce6-Apt). The $\mathrm{Fe}_{3} \mathrm{O}_{4}$-Ce6-Apt nanosystem-based strategy has high sensitivity and requires a short diagnosis turnaround time; thus, it has great potential for early sepsis diagnosis in clinical settings. Moreover, it benefitted from the strong bacteria capture effect of the $\mathrm{Fe}_{3} \mathrm{O}_{4}$-Ce6-Apt nanosystem, achieving complete extracorporeal blood disinfection without transfusion adverse reactions.

Another type of MNPs, superparamagnetic iron oxide NPs (SPIONs), were known as tiny size ( under $20 \mathrm{~nm}$ ), capable of controllable and biocompatible iron oxide NPs. It has led to their numerous biomedical applications: magnetic resonance imaging (MRI) and imaging, hyperthermia for cancer treatment, drug delivery, biosensor systems, magnetic separation immunoassays, parasite diagnostic assays, nano bridges substances for surgery, wound healing, and cell labeling $[64,65]$. SPIONs provided higher magnetic liability to the surrounding magnetic field than other paramagnetic materials. SPIONs have attracted attention in recent years as a nanomedicine, owing to their antibacterial properties. In this context, SPION was reported to activate anti-tumor therapeutic potential by inducing pro-inflammatory macrophage polarization [66]. This idea was further investigated, and a mechanism that promotes the production of IL-10 in macrophages, leading to inhibition of inflammation in LPSinduced sepsis and liver injury, was proposed [53].

In other work, a mannosylated disulfide cross-linked polyethyleneimine (ssPEI-Mannose)-coated bovine serum albumin-reduced $\mathrm{MnO}_{2}\left(\mathrm{BSA}-\mathrm{MnO}_{2}\right)$ was developed (mSPAM), and a nano-assembly was formed to control the $\mathrm{H}_{2} \mathrm{O}_{2}$ levels, an extremely toxic ROS, in LPS-induced systemic and local inflammation mice model [54]. As shown in Fig. 4-2B, the LPS induced inflammation signal was lower in the mSPAM group than in other groups except for the saline group. mSPAM nano-assembly demonstrated efficient anti-inflammatory activities to treat LPS-induced endotoxemia; compared to other groups, the level of IL- 6 and TNF- $\alpha$ reduced until $4 \mathrm{~h}$ and $2 \mathrm{~h}$, respectively [54].

\subsection{Polymer-based nanoparticle}

Polymeric NP drug delivery systems are highly biodegradable and biocompatible. The polymeric NPs can specific targeting, protection of drug molecules, ability to combine therapy and imaging, controlled release, and surface functionalization through diverse precursors $[67,68]$. The encapsulation of cytotoxic chemotherapeutic agents in biodegradable PLGA NPs may offer advantages over other delivery systems. The addition of poly(ethylene glycol) to NP surfaces (PEGylation) was known as a strategy to increase circulation time by opsonization, inhibiting nonspecific protein adsorption and subsequent clearance [69]. 
Table 1 Nanotechnology for sepsis diagnosis

\begin{tabular}{|c|c|c|c|c|}
\hline Agents & Target molecules & Technique & Results & Refs. \\
\hline AuNPs, MNPs & Target DNA & Colorimetric detection & $\begin{array}{l}\text { Detection by naked eyes and metabolic activity assessment of patho- } \\
\text { gens }\end{array}$ & {$[38]$} \\
\hline AuNPs & CRP & Sandwich Immunoassay & $27 \mathrm{pg} / \mathrm{ml}$ of CRP detection within $2 \mathrm{~h}$ & [40] \\
\hline AuNPs & $\mathrm{Cu}^{2+} / \mathrm{NDH}-2$ & Colorimetric detection & E. coli detection with high sensitivity $(40 \mathrm{CFU} / \mathrm{mL}$ ) & {$[41]$} \\
\hline MNPs & $\begin{array}{l}\text { Lipopolysaccharide } \\
\text { (LPS), Endotoxin }\end{array}$ & Magnetic separation & $\begin{array}{l}\text { Rapid, high accuracy of E. coli / S. aureus (6-12 CFU) without blood } \\
\text { culture }\end{array}$ & {$[42]$} \\
\hline Nanobead & PCT & AlphaLISA & Hypersensitive $(18.6 \mathrm{pg} / \mathrm{ml})$ & {$[43]$} \\
\hline AgNPs & LPS & Colorimetric method & $5 \mathrm{nM}$ of LPS detection from urine sample within $5 \mathrm{~min}$ & [44] \\
\hline Magnetic bead & IL-3 in the blood fluid & Electrochemical reaction & Sensitivity $<10 \mathrm{pg} / \mathrm{ml}$ (10 times more sensitive) & [35] \\
\hline
\end{tabular}

Table 2 Nanotechnology for sepsis treatment

\begin{tabular}{|c|c|c|c|c|c|}
\hline & Agents & Size $(\mathrm{nm})$ & Target & Technique & Refs. \\
\hline \multirow[t]{4}{*}{ Metal-based } & AuNPs & 21 & M2 macrophages & $\begin{array}{l}\text { AuNPs own antibiotics effect (only } \\
\text { in vitro test) }\end{array}$ & {$[52]$} \\
\hline & $\mathrm{Fe}_{3} \mathrm{O}_{4}$-Ce6-Apt & 17 & Bacterial colony (live/death) & $\begin{array}{l}\text { Magnetic enrichment for capturing blood } \\
\text { disinfection }\end{array}$ & [42] \\
\hline & SPION & 6.5 & Liver-resident macrophages & $\begin{array}{l}\text { Increasing IL- } 10 \text { and attenuate organ } \\
\text { damage by autophagy }\end{array}$ & [53] \\
\hline & mSPAM & 97 & Intracellular levels of $\mathrm{H}_{2} \mathrm{O}_{2}$ & 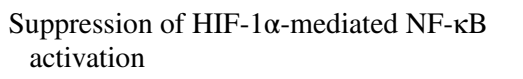 & {$[54]$} \\
\hline \multirow[t]{3}{*}{ Polymer-based } & Atv/PTP-TCeria NPs & 8 & ROS level in kidney & $\begin{array}{l}\text { ROS downregulation drug delivery } \\
\text { (atorvastatin) }\end{array}$ & [48] \\
\hline & CIP-NPs-Abs & 120 & Infectious microenvironments (I-CAM1) & $\begin{array}{l}\text { Co-delivery of antibiotics and anti-inflam- } \\
\text { matory cytokine }\end{array}$ & {$[55]$} \\
\hline & DNase-I pMNSs & 170 & NETosis by Neutrophils & Delivery of DNase-I & {$[56]$} \\
\hline \multirow[t]{3}{*}{ Lipid-based } & $\mathrm{V}_{\mathrm{C}} \mathrm{LNPs}$ & $127-174$ & AMP-Cathepsin B macrophage & Delivery of AMP with CatB mRNA & [47] \\
\hline & M-Lipo & 200 & LPS in the blood fluid & Absorption of LPS and endotoxin & [57] \\
\hline & Leukosome & 94 & Macrophages & $\begin{array}{l}\text { Cytokine control: reduce the pro-inflam- } \\
\text { matory genes (IL- } 6 \text {, IL-1b, and TNF- } \alpha \text { ) } \\
\text { regulation and increase anti-inflamma- } \\
\text { tory ones (IL-10 and TGF- } \beta \text { ) }\end{array}$ & [58] \\
\hline \multirow[t]{2}{*}{ Others } & TMD & - & ROS and RNS & $\begin{array}{l}\text { Scavenging activity and sustainability for } \\
\mathrm{H}_{2} \mathrm{O}_{2}, \mathrm{O}_{2} \cdot-, \mathrm{OH} \text {. }\end{array}$ & [59] \\
\hline & TD-NT & - & $\begin{array}{l}\text { Pro-inflammatory cytokine, DAMP and } \\
\text { PAMP }\end{array}$ & $\begin{array}{l}\text { Charge-dependent (negative) size exclu- } \\
\text { sive }(\sim 50 \mathrm{kDa})\end{array}$ & {$[60]$} \\
\hline
\end{tabular}

In Fig. 5A, a ROS-responsive nano-drug delivery system was designed by combining mitochondria-targeting ceria NPs with atorvastatin for sepsis-induced acute kidney injury (AKI). mPEG-TK-PLGA (PTP) coating significantly improves the biocompatibility and mono-dispersity while prolonging the half-life in the bloodstream. Moreover, it allows NPs to load and release drugs appropriately. Loading atorvastatin (Atv) could help reduced the dosage of ceria NPs and increased the therapeutic effect. The pro-inflammatory cytokine, IL- 6 , and TNF- $\alpha$, demonstrated reduced inflammatory effect and TUNEL assay; the apoptosis cell was lower than AKI groups. TCeria NPs would target mitochondria through triphenylphosphine (TPP)-derived activity to eliminate excessive ROS effectively; the PTP coating and Atv loading demonstrated enhanced anti-inflammatory effect [48].

Other types of polymer-based NPs suggest the codelivery of an antibiotic and anti-inflammatory agent to the injection site; this may be a novel strategy for sepsis therapy because it may concurrently prevent bacterial dissemination and manage inflammation. It designed a novel micelle-structured NP conjugated with an ICAM-1 antibody to target bacterial infectious sites (Fig. 5B). The NPs are coloaded with ciprofloxacin (CIP) and the anti-inflammatory agent (2-[(aminocarbonyl)amino]-5-(4-fluorophenyl)-3-thiophenecarboxamide, TPCA-1) proved helpful in managing 
sepsis provoked by a lethal dose of Pseudomonas aeruginosa in a mouse model of peritonitis. Co-delivery of CIP and TPCA-1 loaded NPs with anti-ICAM-1 groups demonstrated the highest survival rate compared to other groups, showing 90\% survival. The IL-6 and TNF- $\alpha$ also decreased in CIP/ TPCA-1 NPs with anti-ICAM-1, meaning anti-inflammatory effects in bacteria-induced sepsis [55].

In addition, recent studies reported that COVID-19 is associated with neutrophil-specific plasma membrane burst, which releases immoderate NETs and extracellular DNAs (eDNAs). Advanced stages of COVID-19 have exhibited a hyper-inflammatory state, known as a 'cytokine storm', along with sepsis and acute respiratory distress syndrome (ARDS) [70]. A recently published paper proposed the demonstration of DNase-I-coated melanin-like nanospheres (DNase-I pMNSs) for modulation of sepsis-associated NETosis dysregulation (Fig. 5C). Polydopamine-based DNase-I pMNSs have a structure similar to squid ink and melanin. DNase-I was readily attached to the NPs' surface using the excellent adhesive properties of polydopamine. Therapeutic delivery of a DNase-I pMNSs suppressed the eDNA, thereby alleviating sepsis progression in severe COVID-19 patients. This was also confirmed in a CLP-operated septic mouse model. DNase-I pMNSs demonstrated $40 \%$ survival rate for the CLP-operated septic mice for over $132 \mathrm{~h}$ leading to the full recovery of these mice. It is a promising bioinspired vehicle and demonstrates a potential new strategy for SARS-CoV-2-induced sepsis therapy [56].

\subsection{Lipid-based nanoparticle}

Lipid-based nanoformulations exist in various types, such as nano-emulsions, liposomes, and solid lipid NPs (SLNs) frequently applied to transport antibiotics in sepsis. Lipid NPs are advantageous for drug delivery to target cells because they can smoothly merge (endocytosis) with other cell membranes and deliver the loaded antibiotics directly to the target cell cytoplasm. As a carrier, lipid NPs can prolong circulation time and accelerate cellular uptake, countering therapeutic resistance [71]. Lipid nanocarriers, such as nanostructured lipid carriers (NLCs) and nanoemulsions, appear suitable as drug-carrier systems due to their very low cytotoxicity relative to polymeric NPs [72]. As drug carriers, lipid NP releasing mRNA and siRNA have application during sepsis therapy [73].

In this regard, Hou's work aimed to express two substances in macrophages, the antimicrobial peptide (AMP) and cathepsin-B (CatB), which are lethal to sepsis-induced bacteria (Fig. 6A). Vitamin $\mathrm{C}$ lipid NPs (V $\mathrm{C}_{\mathrm{C}} \mathrm{LNP}$ ) loaded AMP-CatB mRNA treated to macrophage, and adoptive transfer macrophages (MACs) can be proved its efficacy for treating multidrug-resistant bacteria-induced sepsis in mice. After screening with MACs, the blood colony-forming unit (CFU) scale was dramatically descended in MACsRAW264.7 groups with intraperitoneal (i.p.) and intravenous (i.v.) treatment. In addition, the survival rate was shown in i.p. and i.v. injected MACs-RAW264.7, approximately $58 \%$, and mouse body weight also increase in MACs-RAWs (i.p. +i.v.) group. Thus, due to the AMP and CatB in macrophages, $\mathrm{V}_{\mathrm{C}} \mathrm{LNPs}$ with mRNA delivery reduce the sepsisinduced bacteria and improve the survival rate, which is the primary strategy for curing patients with sepsis [47].

Biomimetic liposome, a macrophage membrane component mixed with an artificial PEGylated lipid, could stabilize the natural membrane and prolong the circulation in the bloodstream. In Fig. 6B, M-Lipo was synthesized by two membranes that could complement one another and extend their bio function as they integrate. M-Lipo had surface proteins similar to those of macrophages and could substantially adsorb LPS. With assistance from the PEGylated lipids, M-Lipo demonstrated much better stability than the only macrophage membrane (M-membrane) vesicle. In addition, the pharmacokinetic results revealed that M-Lipo had longer retention in blood than the natural M-membrane. By combining these properties, the hybrid M-Lipo reduced the toxicity of LPS in vitro and protected the mouse against endotoxic shock in vivo. Post-injection of M-Lipo in sepsis mice demonstrated $\sim 44 \%$ of survival rate after $24 \mathrm{~h}$. M-Lipo also reduced the inflammatory cytokine level, IL-6, and TNF- $\alpha$, compared to other LPS injected groups. In the histologic analysis, the hepatocytes of LPS treated groups showed partial necrosis (red arrow), but M-Lipo improved LPS-induced liver damage in mice, similar to the non-LPS treating control group [57].

Another team investigated this idea, which evaluated the role of macrophage-derived biomimetic NPs, named leukosomes, in an LPS-mediated murine sepsis model. They demonstrated the interplay of leukosomes with macrophages induced downregulation of pro-inflammatory genes (IL-6, IL- $1 \beta$, and TNF- $\alpha$ ), expression of anti-inflammatory ones (IL-10 and TGF- $\beta$ ), which indirectly elicit an anti-inflammatory response on the endothelial cells. These results showed that the leukosome-mediated inflammatory response regulation in target cells serves as a bioactive nanotherapeutic [58].

\subsection{Other nanomaterials}

NPs are widely known as the most-applicable nanotechnology; it was categorized with different types depending on their particle size, morphology, and physical and chemical properties. Those NP systems with sepsis treatment were based on several materials such as carbon, ceramic, or semiconductor instead of metal, polymeric, and lipid-based NPs [32].

Besides the NP systems, other nanotechnologies have also been reported in the literature aimed at sepsis treatment. One 


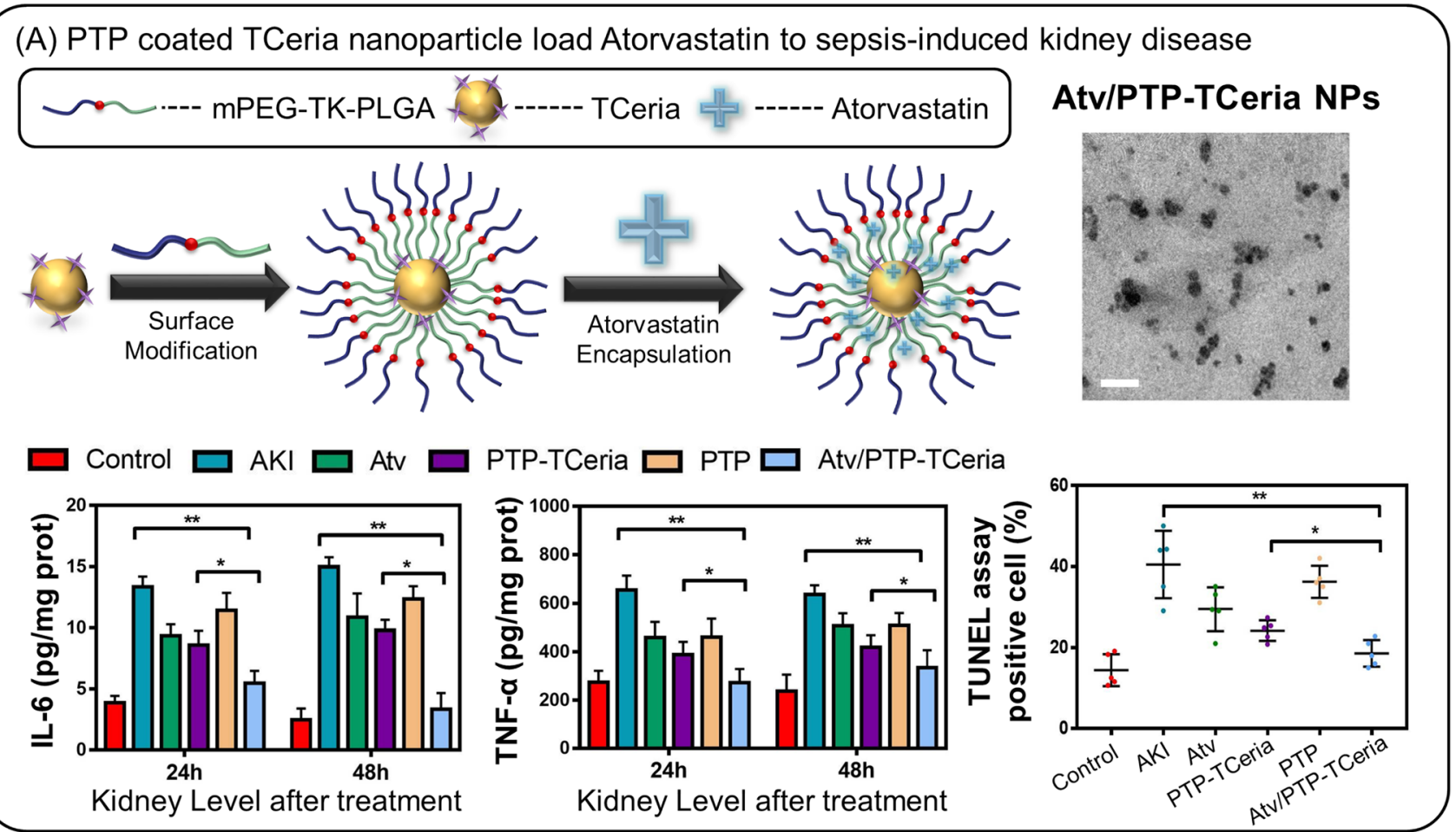

(B) Biofunctional Micelle Structure Nanoparticle using ICAM-1 targeted delivery

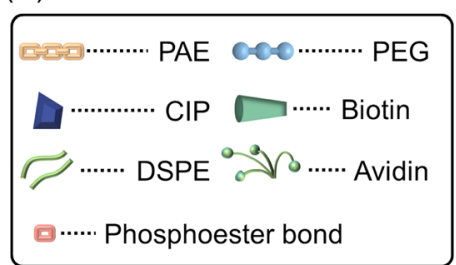

Biotin-PEG-PAE(g-PEG-bDSPE)-b-PEG-Biotin
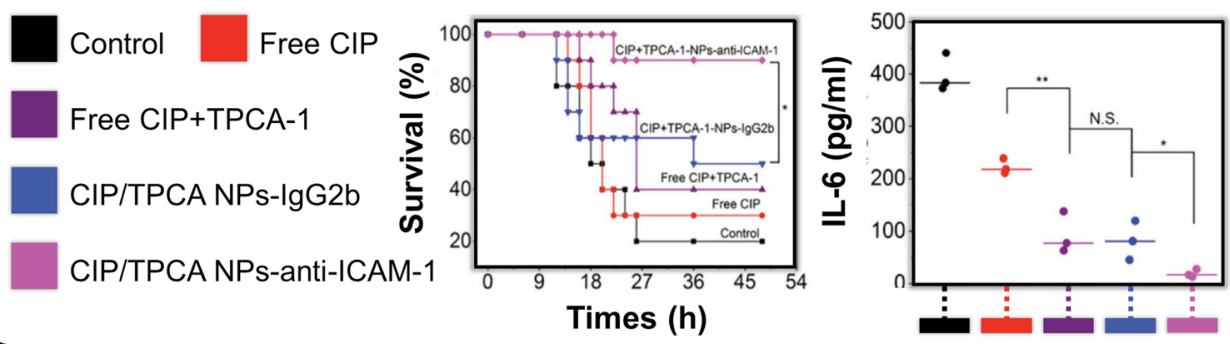

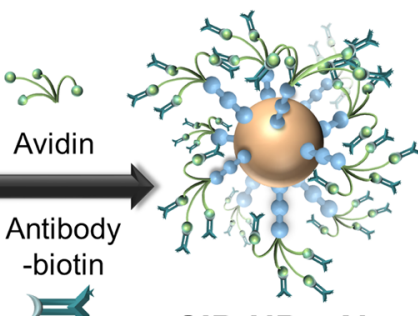

CIP-NPs-Abs

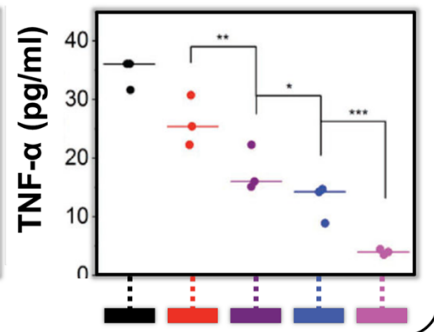

(C) Melanin-based Nanoparticles: DNase-I to Sepsis treatment

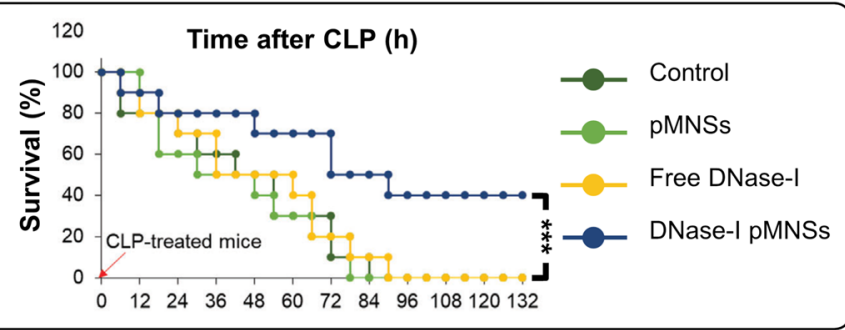

of the studies reports a telodendrimer (TD) nanotrap (NT) to capture cytokines. DAMPs and PAMPs by multivalent, hybrid, and synergistic interactions [59]. The flexible TD scaffold freely changed its conformation by itself and bound with inflammatory mediators effectively. The broad range of inflammatory mediators was combined through multivalent 
४Fig. 5 Polymer-based NPs with sepsis treatment. A ROS-responsive nanodrug delivery system was designed using triphenylphosphine (TPP)-modified Ceria NPs coated with mPEG-TK-PLGA polymer; loading atorvastatin could increase the therapeutic effect of sepsisinduced acute kidney disease. B CIP-TPCA NPs coated with ICAM-1 antibody to target infectious microenvironments have clinical potential in infectious disease and reduce systemic inflammation. C DNase-I pMNSs have the potential of sepsis treatment suggesting the highest survival rate compared to other groups in CLP-treated sepsis mice. It was reproduced with permission from ref. 56. Copyright 2020 Advanced Science

hydrophobic and electrostatic interaction. This study demonstrated a $100 \%$ survival rate of severe in vivo sepsis murine models using optimized TD NT combined with a moderate antibiotic therapy by attenuating hyper inflammation and infection [59].

In a more specific study, the therapeutic efficacy of the 2D shape of transition-metal dichalcogenides (TMD) nanosheets served as an antioxidant through effective scavenging of mitochondrial and intracellular ROS and reactive nitrogen species (RNS) for sepsis treatment. This strategy demonstrated that the therapeutic efficacy of nanosheets significantly reduced the secretion of inflammatory cytokines in the cells, whereas anti-inflammatory cytokine and ROS-producing enzymes were not affected and manifested in severe CLP-induced bacteremia mouse models [60]

\section{Conclusion}

Sepsis, a dysregulated systemic inflammatory response caused by drug-resistant pathogens, is a major global health issue. Nanotechnology has contributed numerous nanomedicines ever since its inception, including possible treatments for sepsis. In particular, nanotechnology significantly improved the existing challenge of low diagnostic sensitivity, which was considered a disadvantage in diagnosing and treating sepsis. This has significantly contributed to the early diagnosis of sepsis and was directly linked to the improvement of patient survival. In addition, NP technology based on various materials could control the systemic immune response, the most significant challenge in sepsis. Thus, it has established itself as a technology that compensates for the existing shortcomings, such as improving drugs' targetability.

Despite the advancement in nanotechnology, considerable research is required before it can be used in actual treatments. First, nano-based technology requires the utilization of diverse nanomaterials, but most of these nanomaterials have not been approved as pharmaceutically acceptable adjuvants by the FDA. Second, the use of therapeutic and diagnostic nano-based technologies in clinical applications is not yet accepted due to the lack of clinical assessments in terms of long-term safety and biocompatibility. Therefore, clinical evaluation and further optimization of nanotechnologies are imperative. Finally, the detailed mechanisms of sepsis are still unknown. If additional sepsis mechanisms are revealed utilizing advanced nanotechnology, we can expect that the survival rate can increase through early diagnosis and more diverse treatment strategies. Thus, nanotechnology in the diagnosis and therapy of sepsis has ongoing challenges demanding collaborative research with multidisciplinary fields. Furthermore, it is possible to develop an advanced nano-based platform that can be used to treat other infectious diseases. 


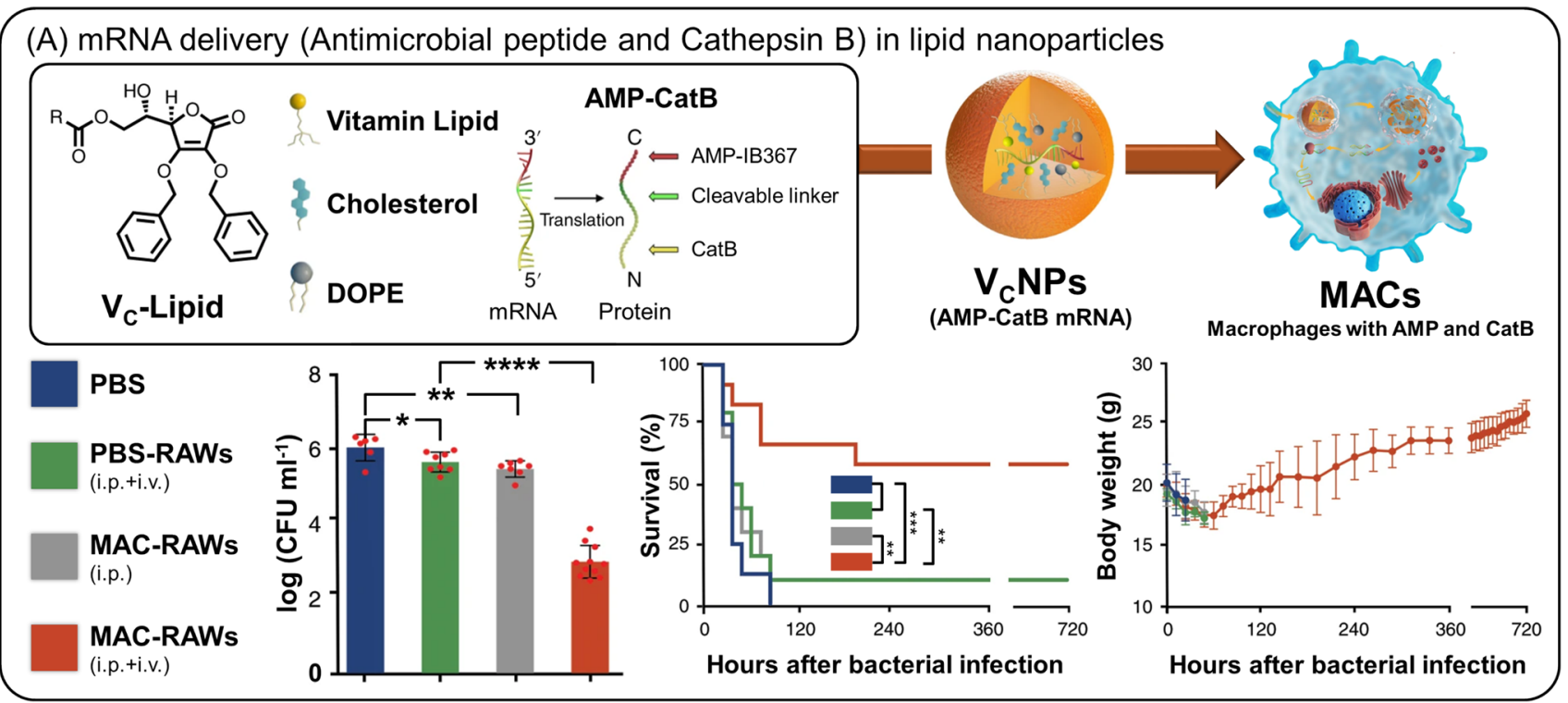

(B) Macrophage membrane isolation and extrusion of lipid NPs

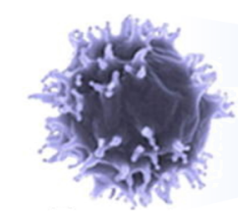

Macrophage

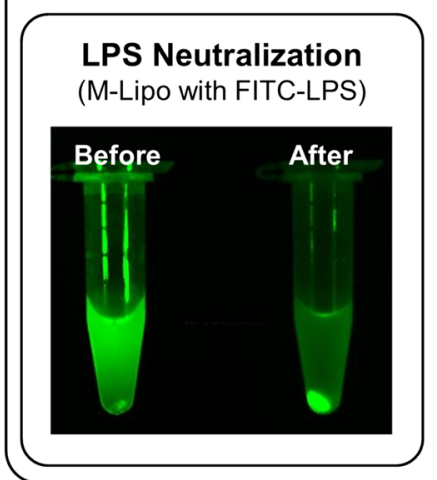

\section{Macrophage membrane Isolation}

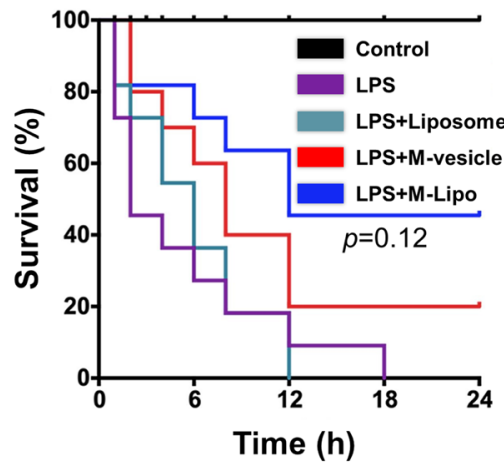

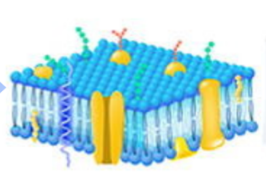

M-membrane

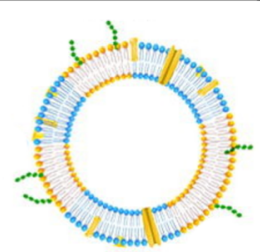

M-Lipo

\section{with Extrusion}

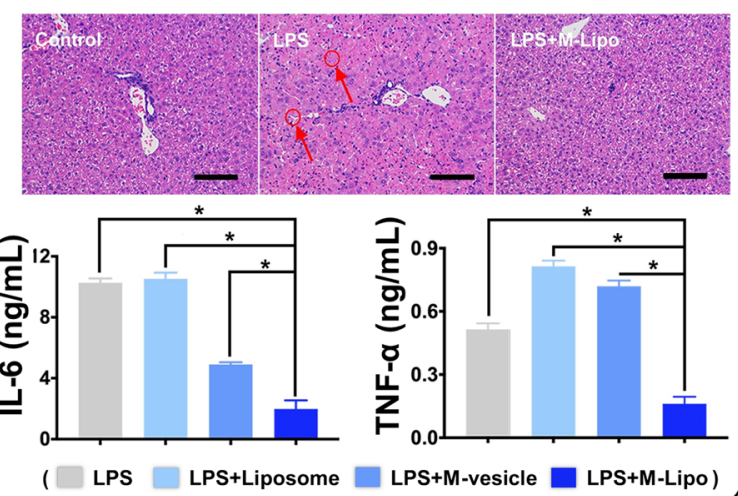

Fig. 6 Lipid-based NPs with sepsis treatment. A MACs comprising vitamin C lipid NPs that deliver antimicrobial peptide and cathepsin B (AMP-CatB) mRNA beneficially improved the bacterial-induced sepsis model's survival rate. B The hybrid liposome, M-Lipo, devel-

Acknowledgements This work was supported by the National Research Foundation of Korea (NRF) Grant funded by the Korean Government (MSIT) (2019R1C1C1006300 and 2019R1A4A1028700).

\section{Declarations}

Conflict of Interest The authors declare that they have no conflict of interest. oped by fusing M-membrane with PEGylated lipids, has advantages in treating sepsis. $(*: p<0.05, * *: p<0.01, * * *: p<0.001$, ****: $p<0.0001)$

\section{References}

1. Bone RC. The sepsis syndrome-definition and general approach to management. Clin Chest Med. 1996;17(2):175-81.

2. Park S, Hong S-B. Treatment guidelines of severe sepsis and septic shock. Neurocrit Care. 2015;8(1):9-15.

3. Labib A. Sepsis care pathway 2019. Qatar Med J. 2020;2019(2):4.

4. Fleischmann C, Scherag A, Adhikari NK, Hartog CS, Tsaganos T, Schlattmann P, Angus DC, Reinhart K. International Forum of 
Acute Care T. Assessment of Global Incidence and Mortality of Hospital-Treated Sepsis. Current Estimates and Limitations. Am J Respir Crit Care Med. 2016;193(3):259-72.

5. Colantuoni A, Martini R, Caprari P, Ballestri M, Capecchi PL, Gnasso A, Lo Presti R, Marcoccia A, Rossi M, Caimi G. COVID19 sepsis and microcirculation dysfunction. Front Physiol. 2020;11:747.

6. Beltran-Garcia J, Osca-Verdegal R, Pallardo FV, Ferreres J, Rodriguez M, Mulet S, Sanchis-Gomar F, Carbonell N, Garcia-Gimenez JL. Oxidative stress and inflammation in COVID-19-associated sepsis: the potential role of anti-oxidant therapy in avoiding disease progression. Antioxidants (Basel). 2020;9(10):936.

7. Beltran-Garcia J, Osca-Verdegal R, Pallardo FV, Ferreres J, Rodriguez M, Mulet S, Ferrando-Sanchez C, Carbonell N, GarciaGimenez JL. Sepsis and coronavirus disease 2019: common features and anti-inflammatory therapeutic approaches. Crit Care Med. 2020;48(12):1841-4.

8. Permyakov NK. Pathology and pathogenesis of sepsis. Arkh Patol. 1992;54(1):9-14.

9. Denning NL, Aziz M, Gurien SD, Wang P. DAMPs and NETs in sepsis. Front Immunol. 2019;10:2536.

10. Cavaillon JM, Singer M, Skirecki T. Sepsis therapies: learning from 30 years of failure of translational research to propose new leads. Embo Mol Med. 2020;12(4):e10128.

11. Markiewski MM, DeAngelis RA, Lambris JD. Complexity of complement activation in sepsis. J Cell Mol Med. 2008;12(6a):2245-54.

12. Assinger A, Schrottmaier WC, Salzmann M, Rayes J. Platelets in sepsis: an update on experimental models and clinical data. Front Immunol. 2019;10:1687.

13. Chousterman BG, Swirski FK, Weber GF. Cytokine storm and sepsis disease pathogenesis. Semin Immunopathol. 2017;39(5):517-28.

14. Aird WC. The role of the endothelium in severe sepsis and multiple organ dysfunction syndrome. Blood. 2003;101(10):3765-77.

15. Schulte W, Bernhagen J, Bucala R. Cytokines in sepsis: potent immunoregulators and potential therapeutic targets-an updated view. Mediat Inflamm. 2013;2013:165974.

16. Perl M, Chung CS, Garber M, Huang X, Ayala A. Contribution of anti-inflammatory/immune suppressive processes to the pathology of sepsis. Front Biosci-Landmrk. 2006;11:272-99.

17. Markiewski MM, Nilsson B, Ekdahl KN, Mollnes TE, Lambris JD. Complement and coagulation: Strangers or partners in crime? Trends Immunol. 2007;28(4):184-92.

18. Kim YC, Lee SE, Kim SK, Jang HD, Hwang I, Jin S, Hong EB, Jang KS, Kim HS. Toll-like receptor mediated inflammation requires FASN-dependent MYD88 palmitoylation. Nat Chem Biol. 2019;15(9):907-16.

19. Osuchowski MF, Welch K, Siddiqui J, Remick DG. Circulating cytokine/inhibitor profiles reshape the understanding of the SIRS/CARS continuum in sepsis and predict mortality. J Immunol. 2006;177(3):1967-74.

20. Hall MW. Immune modulation in pediatric sepsis. J Pediatr Intensive. 2019;8(1):42-50.

21. van der Poll T, van de Veerdonk FL, Scicluna BP, Netea MG. The immunopathology of sepsis and potential therapeutic targets. Nat Rev Immunol. 2017;17(7):407-20.

22. Claxton A, Papafilippou L, Hadjidemetriou M, Kostarelos K, Dark P. The challenge of recognising sepsis: future nanotechnology solutions. J Intensive Care Soc. 2020;21(3):241-6.

23. Gauer RL. Early recognition and management of sepsis in adults: the first six hours. Am Fam Phys. 2013;88(1):44-53.

24. Rhodes A, Evans LE, Alhazzani W, Levy MM, Antonelli M, Ferrer R, Kumar A, Sevransky JE, Sprung CL, Nunnally ME, Rochwerg B, Rubenfeld GD, Angus DC, Annane D, Beale RJ, Bellinghan GJ, Bernard GR, Chiche JD, Coopersmith C, De
Backer DP, French CJ, Fujishima S, Gerlach H, Hidalgo JL, Hollenberg SM, Jones AE, Karnad DR, Kleinpell RM, Koh Y, Lisboa TC, Machado FR, Marini JJ, Marshall JC, Mazuski JE, McIntyre LA, McLean AS, Mehta S, Moreno RP, Myburgh J, Navalesi P, Nishida O, Osborn TM, Perner A, Plunkett CM, Ranieri M, Schorr CA, Seckel MA, Seymour CW, Shieh L, Shukri KA, Simpson SQ, Singer M, Thompson BT, Townsend SR, Van der Poll T, Vincent JL, Wiersinga WJ, Zimmerman JL, Dellinger RP. Surviving sepsis campaign: international guidelines for management of sepsis and septic shock: 2016. Intens Care Med. 2017;43(3):304-77.

25. Bochud PY, Glauser MP, Calandra T. Antibiotics in sepsis. Intensive Care Med. 2001;27:S33-48.

26. Thwaites CL, Lundeg G, Dondorp AM. Recommendations for infection management in patients with sepsis and septic shock in resource-limited settings. Intensive Care Med. 2016;42(12):2040-2.

27. Fujii T, Deane AM, Nair P. Metabolic support in sepsis: corticosteroids and vitamins: the why, the when, the how. Curr Opin Crit Care. 2020;26(4):363-8.

28. Luo G, Zhang J, Sun YQ, Wang Y, Wang HB, Cheng BL, Shu Q, Fang XM. Nanoplatforms for Sepsis management: rapid detection/ warning, pathogen elimination and restoring immune homeostasis. Nanomicro Lett. 2021;13(1):1-64.

29. Yoon MY, Yoon SS. Disruption of the gut ecosystem by antibiotics. Yonsei Med J. 2018;59(1):4-12.

30. Maker JH, Stroup CM, Huang V, James SF. Antibiotic hypersensitivity mechanisms. Pharmacy-Basel. 2019;7(3):122.

31. Turnidge J. Impact of antibiotic resistance on the treatment of sepsis. Scand J Infect Dis. 2003;35(9):677-82.

32. Papafilippou L, Claxton A, Dark P, Kostarelos K, Hadjidemetriou M. Nanotools for sepsis diagnosis and treatment. Adv Healthc Mater. 2021;10(1):2001378.

33. Jin S, Ye K. Nanoparticle-mediated drug delivery and gene therapy. Biotechnol Prog. 2007;23(1):32-41.

34. Pant A, Mackraj I, Govender T. Advances in sepsis diagnosis and management: a paradigm shift towards nanotechnology. J Biomed Sci. 2021;28(1):6.

35. Min J, Nothing M, Coble B, Zheng H, Park J, Im H, Weber GF, Castro CM, Swirski FK, Weissleder R, Lee H. Integrated biosensor for rapid and point-of-care sepsis diagnosis. ACS Nano. 2018;12(4):3378-84.

36. Zhang Y, Li M, Gao X, Chen Y, Liu T. Nanotechnology in cancer diagnosis: progress, challenges and opportunities. J Hematol Oncol. 2019;12(1):137.

37. Mieszawska AJ, Mulder WJ, Fayad ZA, Cormode DP. Multifunctional gold nanoparticles for diagnosis and therapy of disease. Mol Pharm. 2013;10(3):831-47.

38. Hill HD, Mirkin CA. The bio-barcode assay for the detection of protein and nucleic acid targets using DTT-induced ligand exchange. Nat Protoc. 2006;1(1):324-36.

39. Draz MS, Shafiee H. Applications of gold nanoparticles in virus detection. Theranostics. 2018;8(7):1985-2017.

40. Belushkin A, Yesilkoy F, Altug H. Nanoparticle-enhanced plasmonic biosensor for digital biomarker detection in a microarray. ACS Nano. 2018;12(5):4453-61.

41. Mou XZ, Chen XY, Wang JH, Zhang ZT, Yang YM, Shou ZX, Tu YX, Du XC, Wu C, Zhao Y, Qiu L, Jiang PJ, Chen CY, Huang DS, Li YQ. Bacteria-Instructed click chemistry between functionalized gold nanoparticles for point-of-care microbial detection. Acs Appl Mater Interfaces. 2019;11(26):23093-101.

42. Wang JH, Wu H, Yang YM, Yan R, Zhao Y, Wang YH, Chen AH, Shao SL, Jiang PJ, Li YQ. Bacterial species-identifiable magnetic nanosystems for early sepsis diagnosis and extracorporeal photodynamic blood disinfection. Nanoscale. 2018;10(1):132-41. 
43. Li P, Chen ZH, Liu B, Li K, Wang H, Lin L, He L, Wei J, Liu TC. Establishment of a novel homogeneous nanoparticle-based assay for sensitive procalcitonin detection of ultra low-volume serum samples. Int J Nanomed. 2018;13:5395-404.

44. Liu T, Gao LQ, Zhao J, Cao Y, Tang YG, Miao P. A polymyxin B-silver nanoparticle colloidal system and the application of lipopolysaccharide analysis. Analyst. 2018;143(5):1053-8.

45. Yuk SA, Sanchez-Rodriguez DA, Tsifansky MD, Yeo Y. Recent advances in nanomedicine for sepsis treatment. Ther Deliv. 2018;9(6):435-50.

46. Lakkireddy HR, Bazile DV. Nano-carriers for drug routeingtowards a new era. J Drug Target. 2019;27(5-6):525-41.

47. Hou XC, Zhang XF, Zhao WY, Zeng CX, Deng BB, McComb DW, Du S, Zhang CX, Li WQ, Dong YZ. Vitamin lipid nanoparticles enable adoptive macrophage transfer for the treatment of multidrug-resistant bacterial sepsis (vol 15, pg 41 2020). Nat Nanotechnol. 2020;15(7):615.

48. Yu H, Jin FY, Liu D, Shu GF, Wang XJ, Qi J, Sun MC, Yang P, Jiang SP, Ying XY, Du YZ. ROS-responsive nano-drug delivery system combining mitochondria-targeting ceria nanoparticles with atorvastatin for acute kidney injury. Theranostics. 2020;10(5):2342-57.

49. Qie YQ, Yuan HF, von Roemeling CA, Chen YX, Liu XJ, Shih KD, Knight JA, Tun HW, Wharen RE, Jiang W, Kim BYS. Surface modification of nanoparticles enables selective evasion of phagocytic clearance by distinct macrophage phenotypes. Sci Rep-Uk. 2016;6(1):1-11.

50. Huang M, Cai SL, Su JQ. The pathogenesis of sepsis and potential therapeutic targets. Int J Mol Sci. 2019;20(21):5376.

51. Hattori Y, Hattori K, Suzuki T, Matsuda N. Recent advances in the pathophysiology and molecular basis of sepsis-associated organ dysfunction: novel therapeutic implications and challenges. Pharmacol Therapeut. 2017;177:56-66.

52. Taratummarat S, Sangphech N, Vu CTB, Palaga T, Ondee T, Surawut S, Sereemaspun A, Ritprajak P, Leelahavanichkul A. Gold nanoparticles attenuates bacterial sepsis in cecal ligation and puncture mouse model through the induction of M2 macrophage polarization. BMC Microbiol. 2018;18(1):1-10.

53. Xu YJ, Li Y, Liu XH, Pan YC, Sun ZH, Xue YX, Wang TT, Dou H, Hou YY. SPIONs enhances IL-10-producing macrophages to relieve sepsis via Cav1-Notch1/HES1-mediated autophagy. Int J Nanomed. 2019;14:6779-97.

54. Rajendrakumar SK, Revuri V, Samidurai M, Mohapatra A, Lee JH, Ganesan P, Jo J, Lee YK, Park IK. Peroxidase-mimicking nanoassembly mitigates lipopolysaccharide-induced endotoxemia and cognitive damage in the brain by impeding inflammatory signaling in macrophages. Nano Lett. 2018;18(10):6417-26.

55. Zhang CY, Gao J, Wang ZJ. Bioresponsive nanoparticles targeted to infectious microenvironments for sepsis management. Adv Mater. 2018;30(43):1803618.

56. Park HH, Park W, Lee YY, Kim H, Seo HS, Choi DW, Kwon HK, Na DH, Kim TH, Choy YB, Ahn JH, Lee W, Park CG. Bioinspired DNase-I-coated melanin-like nanospheres for modulation of infection-associated NETosis dysregulation. Adv Sci. 2020;7(23):2001940.

57. Jiang LX, Li RX, Xu JZ, Luan PW, Cui QF, Pang ZQ, Wang JX, Lin GQ, Zhang JG. Endotoxin-adsorbing macrophagemimetic hybrid liposome for sepsis treatment. Chem Eng J. 2019;371:15-25.

58. Molinaro R, Pasto A, Corbo C, Taraballi F, Giordano F, Martinez JO, Zhao PC, Wang X, Zinger A, Boada C, Hartman KA, Tasciotti
E. Macrophage-derived nanovesicles exert intrinsic anti-inflammatory properties and prolong survival in sepsis through a direct interaction with macrophages. Nanoscale. 2019;11(28):13576-86.

59. Shi CY, Wang XJ, Wang LL, Meng QH, Guo DD, Chen L, Dai M, Wang GR, Cooney R, Luo JT. A nanotrap improves survival in severe sepsis by attenuating hyperinflammation. Nat Commun. 2020;11(1):1-13.

60. Yim D, Lee DE, So Y, Choi C, Son W, Jang K, Yang CS, Kim JH. Sustainable nanosheet antioxidants for sepsis therapy via scavenging intracellular reactive oxygen and nitrogen species. ACS Nano. 2020;14(8):10324-36.

61. Khan ST, Musarrat J, Al-Khedhairy AA. Countering drug resistance, infectious diseases, and sepsis using metal and metal oxides nanoparticles: current status. Colloid Surface B. 2016;146:70-83.

62. Li JJ, Cha RT, Zhao XH, Guo HB, Luo HZ, Wang MZ, Zhou FS, Jiang XY. Gold nanoparticles cure bacterial infection with benefit to intestinal microflora. ACS Nano. 2019;13(5):5002-14.

63. Myronov P, Bugaiov V, Holubnycha V, Sikora V, Deineka V, Lyndin M, Opanasyuk A, Romaniuk A, Pogorielov M. Low-frequency ultrasound increase effectiveness of silver nanoparticles in a purulent wound model. Biomed Eng Lett. 2020;10(4):621-31.

64. Miguel MG, Lourenco JP, Faleiro ML. Superparamagnetic iron oxide nanoparticles and essential oils: a new tool for biological applications. Int J Mol Sci. 2020;21(18):6633.

65. Singh RK, Kim HW. Inorganic nanobiomaterial drug carriers for medicine. Tissue Eng Regen Med. 2013;10(6):296-309.

66. Zhao JJ, Zhang ZK, Xue YX, Wang GQ, Cheng Y, Pan YC, Zhao SL, Hou YY. Anti-tumor macrophages activated by ferumoxytol combined or surface-functionalized with the TLR3 agonist poly (I : C) promote melanoma regression. Theranostics. 2018;8(22):6307-21.

67. Sur S, Rathore A, Dave V, Reddy KR, Chouhan RS, Sadhu V. Recent developments in functionalized polymer nanoparticles for efficient drug delivery system. Nano-Struct Nano-Objects. 2019;20:100397.

68. Gessner I, Neundorf I. Nanoparticles modified with cell-penetrating peptides: conjugation mechanisms, physicochemical properties, and application in cancer diagnosis and therapy. Int J Mol Sci. 2020;21(7):2536.

69. Suk JS, Xu QG, Kim N, Hanes J, Ensign LM. PEGylation as a strategy for improving nanoparticle-based drug and gene delivery. Adv Drug Deliver Rev. 2016;99:28-51.

70. Gupta S, Sahni V. The intriguing commonality of NETosis between COVID-19 \& Periodontal disease. Med Hypotheses. 2020;144:109968.

71. Filipczak N, Pan JY, Yalamarty SSK, Torchilin VP. Recent advancements in liposome technology. Adv Drug Deliver Rev. 2020;156:4-22.

72. Naseri N, Valizadeh H, Zakeri-Milani P. Solid lipid nanoparticles and nanostructured lipid carriers: structure, preparation and Application. Adv Pharm Bull. 2015;5(3):305-13.

73. Saunders NRM, Paolini MS, Fenton OS, Poul L, Devalliere J, Mpambani F, Darmon A, Bergere M, Jibault O, Germain M, Langer R. A nanoprimer to improve the systemic delivery of siRNA and mRNA. Nano Lett. 2020;20(6):4264-9.

Publisher's Note Springer Nature remains neutral with regard to jurisdictional claims in published maps and institutional affiliations. 